\title{
Bir Havayolu İşletmesinde Kabin Ekiplerinin Performans Değerlendirmesine İlişkin bir Veri Madenciliği Uygulaması
}

\author{
Büşra YILDIZ KORKMAZ ${ }^{*}$, Uğur ÖZCAN ${ }^{1}$ \\ ${ }^{1}$ Gazi Üniversitesi, Mühendislik Fakültesi, Endüstri Mühendisliği Bölümü, Ankara, Türkiye
}

Geliş Tarihi:30.10.2018

"Sorumlu Yazar: busraydz@gmail.com

Kabul Tarihi:27.11.2018

\section{$\ddot{O} z$}

Günümüzde işletmeler gerek piyasaya tutunmak gerekse her geçen gün gelişmekte olan teknolojiyi yakalamak adına yoğun bir rekabet içerisindedirler. Yoğun rekabet ortamı mevcut müşteriyi tutma ve yeni müssteri kazanma amacını da beraberinde getirmektedir. Havayolu işletmelerinde yolculara beklentilerinin ötesinde hizmet sunma noktasında kabin ekibinin etkisi büyüktür. Bir havayolu işletmesinde 3764 kabin memurunun 2015 yllında performans değerlendirmeleri incelenmiştir. Yapılan bu performans değerlendirmelerinin sonucunda karne düzeyleri belirlenmektedir. Bu çalışmanın amacı 2015 yılındaki karne düzeyleri için; kabin memurlarının yetkinlik bazlı değerlendirme puanları ile demografik özellikleri arasında anlamlı bir kural oluşturmaktır. Bu çalışmada, açık kaynak kodlu JAVA dilinde geliştirilmiş WEKA programı ile veri madenciliği yöntemlerinden karar ağacı algoritmaları kullanılmıştır. Oluşturulan karar ağacı algoritmalarından sınıflandırma doğruluğu açısından en başarılı algoritma olarak Random Forest ve ikinci olarak J48 algoritması tespit edilmiştir. Random Forest algoritma çıktısı görsel bir sonuç vermeyip algoritma adımlarını görülmeyecek şekilde vererek karmaşık bir yapı oluşmasından dolayı çalışma J48 algoritmasına göre yorumlanmıştır. Ayrıca, WEKA programında nitelik seçimi özelliği ile InfoGainAttributeEval algoritması ile "Ranker" metodu uygulanması sonucunda çıktıların J48 algoritması çıktıları ile aynı doğrultuda olduğu tespit edilmiştir. Bu bağlamda kabin memurlarının karne düzeylerini en çok etkileyen niteliğin "sürekli öğrenme ve kişisel gelişim" olduğu ve demografik özellikler ile karne düzeyi arasında anlamlı kural olmadığı tespit edilmiştir.

Anahtar Kelimeler: Performans Değerlendirme, Kabin memuru, Veri Madenciliği, Karar Ağaçları, Havayolu

\section{A Data Mining Application for Performance Evaluation Cabin Crew Members in an Airline Company}

\begin{abstract}
Nowadays, the companies are in competition fiercely both for keeping market and catching the developing technology. The fierce competition environment aims to keep current customers and gain new customers. The impact of cabin crew is great that serving which is beyond the expectations of passengers in airline company. Performance evaluations of 3764 cabin crew members were examined in 2015 in an airline company. The levels of scorecard are determined as a result of making these evaluations. The objective of this study is making meaningful rule between evaluation scores based on competence and demographic features for the levels of scorecard in 2015. In this study, WEKA was used, which is developed in open source code JAVA, and decision tree algorithms which is one of data mining methods. It was explored that Random Forest algorithm was the best algorithm and second one was J48 algorithm in terms of true positive rate in generated decision tree algorithms. This study was interpreted according to the J48 algorithm because Random Forest algorithm output was not suitable for this study due to nonvisual output and complex structure in steps of the algorithm. In addition, it was used for attribute selection with Ranker method in "InfoGainAttributeEval" algorithm and the results was detected similar to J48 algorithm outputs. In this regard, it was determined that the most important attribute affecting cabin crew scorecard levels was "Continuous learning and personal development" and no meaningful rule between demographic attributes and scorecard level.
\end{abstract}

Keywords: Performance Evaluation, Cabin Crew, Data Mining, Decision Tree, Airline 


\section{Giriş}

Günümüzde işletmeler gerek piyasaya tutunmak gerekse her geçen gün gelişmekte olan teknolojiyi yakalamak adına yoğun bir rekabet içerisindedirler. Yoğun rekabet ortamı mevcut müşteriyi tutma ve yeni müşteri kazanma amacını da beraberinde getirmektedir.

İşletmeler öngördükleri sonuçlara ulaşarak etkinliği veya kaynakları uygun bir şekilde kullanarak verimliliği sağlama amaçları, performans değerlendirmesini önemli kılmaktadır.

Performans yönetimi, belirlenen amaçlara ulaşmak için mevcut durum ve istenen durum arasındaki kıyaslamayı yaparak sürekli iyileştirme sağlayan bir mekanizmadır. İşletmeler değişen çevre koşullarında rekabet güçlerini arttırmak amacıyla stratejik planlarına ve hedeflerine ne derece ulaştıklarının tespiti için sadece finansal boyutta değerlendirme yapan geleneksel performans ölçütleri ile değil çok ölçütlü performans değerlendirmelerini kullanmaya başlamışlardır. Finansal boyutun yanı sıra müşteri boyutu, içsel işlemler boyutu, bilgi ve öğrenme boyutu ile performans değerlendirmelerinin alt yapısı oluşmaktadır.

İşletmelerin geleneksel performans ölçütlerini kullanmamasının sebepleri arasında, kısa dönem odaklı olması, geçmişe yönelik olması ve işletmedeki birçok bölüm ile alakalı olmaması gibi bu yetersizlikler de yer almaktadır. Kurumsal Karne (Dengeli Başarı Göstergesi), geçmişe yönelik verileri iz gösterge olarak belirlemiş, işletmeyi bir bütün olarak değerlendiren ve stratejilerin uygulamaya dönüştüren tüm boyutları ile dengeli bir performans ölçümü sağlamaktadır.

Türkiye'de faaliyet gösteren bir havacılık işletmesinde kabin memurlarının performans değerlendirmesi hali hazırda uygulanmaktadır. Kabin memurlarının gerçekleştirdikleri tarifeli dış hat seferlerinde, kabin amirleri tarafından performans değerlendirmesine tabi tutulmaktadır. $\mathrm{Bu}$ performans değerlendirmelerinin sonucu olarak her 3 aylık dönemde kurumsal karneleri yayımlanmaktadır. Değerlendirme ölçütleri, işletmenin misyon, vizyon ve stratejik hedefleri doğrultusunda mesleki yetkinlik bazlı kriterlerden oluşmaktadır. Mesleki yetkinlikler işletmedeki yöneticiler tarafından kabin memurlarından beklenen yetkinlikler olarak belirlenmiştir.

Başka bir deyişle, yolcu ile birebir iletişime geçen kabin memurlarının performans değerlendirmeleri sayesinde kurumsal farkındalık izlenimi yaratmaları sağlanmakta ve hızlı aksiyon alınabilmektedir.

Kabin memurlarının 3 aylık dönemde yayımlanan yetkinlik bazında kurumsal karne sonuçları yıl bazında oluşturulmuş ve akabinde yıl bazında belirlenmiş olan performans değerlendirmelerinde; mesleki yetkinliklerinin ve demografik verilerinden hangi niteliklerin önemli olduğu konusunda anlamlı kural oluşturulmuştur. 
Havacılık sektöründe performans değerlendirmesi ile ilgili yapılmış çalışmalar mevcuttur. Çalışmalar incelendiğinde çoğunlukla istatistiksel yöntemler uygulanarak yapılmış olan çalışmalar bulunmaktadır.

“Öngörülen mesleki başarı da verimlilik testinin etkililiğinin belirlenmesi” çalışması için başlangıçta 136 kabin memuru 16 PF Kişilik Envanterini (16 temel kişilik Özelliğini ve 5 genel kişilik eğilimini ölçen kişilik envanteri) tamamlamışlardır. 6 aylık bir zamanda uçuştaki davranışları günlük olarak rapor halinde tutulmuştur. Bu rapor daha sonra ortalama altı, ortalama ve ortalama üstü olarak kategorize edilmek için havayolundan kimlerin ayrılacağını saptamak için kullanılmıştır. Bazı trendler belli olmasına rağmen, Pearson korelasyonu ve tek yönlü ANOVA analizi anlamlı farklılıklar için çeşitli gruplarda (ortalama altı-ortalama) başarısız olmuştur (Furnham, 1991).

Malezya havayollarında yapılmış olan çalışmada havacılık misafirperverliğinin altında yatan boyutları açığa çıkarılmıştır. Bu çalışma havacılık misafirperverliğini kabin ekibi performansına veya ev sahipliği davranışına dayandırarak tarif etmiştir. Bugünün havayolu taşımacılık endüstrisi oldukça yoğun bir şekilde rekabet içerisinde olmasından dolayı havayolu şirketleri sadece ayırt edici servis sunma değil uçuş boyunca misafirperver servis yollarını bulmak zorundadır.391 yolcunun içerdiği ilk data seti üzerinde yapılan keşfedici faktör analizinin sonucuna istinaden misafirperverlik total varyansın \%67'sinden gelen 4 boyut içerdiği yönünde sonuçlanmıştır (Nameghi ve Ariffin, 2013).

X Hava Yolları'nda dış hat uçuşları esnasında 511 yolcu ile yapılmıştır. Araştırmanın sonucu olarak; hizmet kalitesinin algılamasında, yolcuların memnuniyet seviyelerinde en etkili faktörün “anında hizmet faktörü” olduğu tespit edilmiştir. Bu faktörü; "güvenilir ve doğru hizmet”, "güven telkin etme" ve "müşteriyi tanıma-anlama" faktörleri devam ettirmektedir (Okumuş ve Asil, 2007).

2008 yılında kurulmuş olan Anadolu Jet'in iç hatlardaki müşteri profilini meydana çıkarmak ve hizmet kalitesini ölçümlemek amaçlanmıştır. Yolculara, SERVQUAL kalite ölçüm modeli ile oluşturmuş bir anket uygulaması yapılmıştır. Anket sonuçlarına göre hizmet kalemlerinin boşluk analizleri hesaplanmış, Anadolu Jet'in müşteri memnuniyeti açısından beklentinin yükssek, algının düşük olduğu hizmet kalemleri ortaya çıkarılmıştır. SERVQUAL skorlarına göre; yolcuların genel anlamda; çalışanların zamanında, hızlı ve doğru bilgi vermeleri, saygılı olmaları, teknik bilgi ve yeteneklerinin yeterli olması, uçuş arızası, uçuş iptal edilme/ertelenme olasılığının düşük olması önermelerinden memnun olduklarını göstermektedir (Hatipoğlu ve Işık, 2015).

THY diş hat yolcularıyla yapmış olduğu çalışmada, SERVQUAL modeli ile hizmet kalitesini değerlendirmiştir. Dış hat yolcularının, kalite boyutları içerisinde sırayla isteklilik, güvenilirlik, teminat ve empati boyutlarına önem verdiği; fiziki unsurların, memnuniyet üzerinde anlamlı bir 
etkisinin olmadığı saptanmıştır. Ek olarak, Türk ve yabancı yolcu profillerinin daha ayrı bir kalite beklentisine sahip olduğunu ortaya çıkarmıştır (Alkoç, 2004).

Ayrıca, havacılık sektöründe yapılan çalışmalarda veri madenciliği yönteminin kullanıldığı bazı çalışmalar da incelenmiştir.

Pritscher'e göre havayolu işletmelerinde veri madenciliğinin en açık bir şekilde uygulanabileceği alan sık uçanlar programlarıdır. Avrupa'nın ana havayolu ittifaklarından biri olan Qualiflyer'de yapılan bir çalışmada CRM'in başarılı bir şekilde uygulanmasını desteklemek için veri madenciliği yöntemleri kullanılmış. Buradaki çalışmada ilk iş yüksek kâr potansiyeline sahip müşterilerin pazar segmentini belirlemek olmuştur (Pritscher ve Feyen, 2011).

Veri madenciliği tekniklerini kullanarak Ethiopian Havayolları ile uçanların kazanacakları puanları tahmin etmeye çalışmış. Bu çalışmada yapay sinir ağları, çok katmanlı perceptron ve geriye yönelik ağlar ve radyal temelli fonksiyon mimarisi kullanılmış. Yapılan bu çalışmanın sonunda ortalama \%33 - 37 hata oranına ulaşılmış. Sistemin daha fazla eğitilmesiyle daha başarılı sonuçlar elde edilebileceğine inanılmaktadır. Ethiopian Havayollarında karar vermeye destek olabilmek için veri madenciliği tekniklerinin daha fazla kullanılması gerektiğine inanmaktadır (Gobena, 2000).

Eskişehir'de havayolu yolcu potansiyelinin tespit edilmesi amacıyla bir karar ağacı uygulamasında; havayolu yolcu taşımacılığında olan potansiyel yolcu talebinin ölçülmesi ve kentin sosyoekonomik gelişimine yarar sağlayacak çapraz havayolu uçuşlarının gerçekleşmesi için gerekli verileri karar ağacı modeli ile seyahat etme oranının en yüksek olduğu yolcu kesimi tespit edilmek istenmektedir (Y1lmaz ve ark. , 2017).

Havacılık sektöründe veri madenciliği ile yapılan çalışmalarda yolcu memnuniyetine etki eden dış faktörleri belirlemek adına yapılmıştır. Bu çalışmada yolcu memnuniyetine direkt olarak etki eden ve yolcuların seyahat deneyimlerinde etkisi yadsınamaz ölçüde olan kabin memurlarının uçuş bazında performans değerlendirmeleri incelenmiş ve performans ölçütünü en çok etkileyen özellik saptanmaya çalışılmıştır.

\section{Materyal ve Metot}

\subsection{Materyal}

Bir havayolu işletmesinde, kabin memurlarının dış hat tarifeli uçuşlarda performans değerlendirmesi gerçekleştirilmektedir. Kabin memurlarının görev ve yetkinliklerine ilişkin belirlenmiş olan standartlara ne kadar uyum sağladıklarının ölçümlenmesinde yararlanılan performans değerlendirmesinin sonuçları büyük önem arz etmektedir. 
İşletmenin vizyon ve misyon hedefleri doğrultusunda belli yetkinlikler çerçevesinde kabin memurları, dış hat tarifeli her uçuş sonrasında sistem tarafından kabin amirlerine atanan formlar aracılığıyla değerlendirilmektedirler. Kabin ekipleri her uçuşunda farklı ekipler ile görev icra etmelerinden dolayı bu sürecin avantajları; tek bir değerlendirenin değil çok sayıda değerlendiren personel olması sebebiyle insani faktörlerden oluşabilecek hataları minimize etmekte ve işletmenin hedefleri doğrultusunda kaliteyi arttırmanın yolunu açmaktadır.

İlgili değerlendirme formlarında olan 6 mesleki yetkinlik ve bu yetkinliklerin 10 alt yetkinliğine göre kabin memurları değerlendirilmektedir. Değerlendirmelerdeki istatistiksel hesaplamalar sonucunda, kabin memurlarının her 3 ayda bir kurumsal karne olarak kurumsal karne düzeyi ve puanları yayımlanmaktadır. Çalışmada mesleki yetkinliklerin yanı sıra 7 demografik veriden yararlanılmış ve etkisi ölçümlenmiştir.

2015 yılında üçer aylık dönemlerde kabin memurlarının yetkinlik bazlı performans değerlendirmeleri; yıl bazında birleştirerek tek bir kurumsal karne meydana getirilmiştir. Mesleki yetkinlik ve demografik veriler arasından, karne düzeyini en çok etkileyen niteliği saptamak için karar ağacı algoritmalarından faydalanılmıştır. Bu bağlamda öncelikle 2015 yılı Ocak-Aralık ayları için 18 farklı değişken için 3764 x 18'lik bir veri kümesi hazırlanmıştır.

\subsection{Metot}

\subsubsection{Veri Madenciliğ i}

Veri tabanlarından bilgi keşfinin konusu ilk kez 1989 yılında A.B.D’nin Detroit Eyaleti’nde gerçekleştirilen 11. Uluslararası Müşterek Yapay Zekâ Konferansı'nda ele alınmıştır (Piatetsky ve Shapiro,1990). Veri madenciliği, veri ambarlarında bulunan verilerden otomatikleşmiş modellere göre anlamlı kuralları, ilişkileri, davranışları elde etme gibi ayrıca bir tanımlanma yapılmaktadır. $\mathrm{Bu}$ aşamada, veri içinde daha önceden bilinmeyen veya muhakeme edilemeyen desenler (pattern) ilk olarak elde edilmektedir. $\mathrm{Bu}$ desenler çoğunlukla kurallar arasındaki ilişkilerin, sıralamanın, sınıflandırmanın, veri birlikteliğinin ve tahminlemenin neticesinde belirlenmektedir (Mitra ve Acharya, 2003).

Özetle veri madenciliği, mevcut veriler içerisinden açık olarak ifade edilmeyen, net olmayan, önceden muhakeme edilemeyen bilgilerden potansiyel yararlı bilginin elde edilmesidir (Alataş ve Akin, 2004).

Veri madenciliği sürecini CRISP-DM süreci 6 aşamada belirtmek mümkündür.

- Problemin Tanımlanması

- Verinin Hazırlanması 
- Modelin Kurulması

- Modelin Değerlendirilmesi

- $\quad$ Modelin Kullanılması

- $\quad$ Modelin İzlenmesi

Bu çalışma CRISP-DM sürecine göre ilerlemektedir.

Veri madenciliği uygulamalarında yararlanılan modeller; tahmin edici (Predictive) ve tanımlayıcı (Descriptive) modeller halinde ayrılabilmektedir. Tahmin edici modeller; neticeleri belli olan verilerden başlayarak bir model geliştirerek neticeleri bilinmeyen verilerin sonuçlarını öngörülmesi hedeflenmektedir. Tanımlayıcı modeller; karar vermeye öncülük etmede faydalanabilecek hali hazırda verilerdeki örüntülerin bilinmesidir. Veri madenciliği, sınıflandırma, kümeleme, kural çıkarımı, benzerlik tespiti ve tanımlama gibi fonksiyonları uygulamaktadır (Emekci ve ark. , 2007).

Sinıflama ve regresyon modelleri tahmin edici (predictive) modeller olarak bilinir. Kümeleme ve birliktelik kuralları modelleri ise tanımlayıcı (descriptive) modeller olarak nitelendirirler (Özekes ve Çamurcu, 2002).

Veri madenciliği modelleri yaptıkları işlemlere göre 3 temel başlık altında toplanabilir. $\mathrm{Bu}$ başlıklar:

1. Sinıflama (Classification) ve Regresyon (Regression): Sınıflama kategorik değerlerin tahmin edilmesinde kullanılırken regresyon süreklilik gösteren değerleri tahmin etmek için kullanılmaktadır. Sınıflama ve Regresyon modelleri arasında bulunan farklılık, tahmin edilen bağımlı değişken kategorik ya da sürekli olup olmadığını gösteren durumdur. Fakat, bazı tekniklerde her iki modelin gitgide birbirlerine yaklaşması; aynı tekniklerden faydalanılmasına sevk etmektedir (Kalıkov, 2006). Sinıflandırma algoritmaları ise, Karar ağaçları, NaiveBayes, Diskriminant analizi, Sinir ağları, Kaba kümeler, Genetik algoritmalar ve Regresyon Analizi olarak bilinmektedir.

2. Kümeleme (Clustering): Kümeleme, veri tabanından ilginç örüntülerin keşfedildiği bir madencilik tekniğidir. Kümelemenin genel düşüncesi, veri tabanını çok sayıda kümeye ayırmak ve aynı kümeye ait verilerin mümkün olduğu kadar yakın ilişkide olmalarının sağlanmasıdır (Hsu, 2008). Sınıflama ve kümeleme arasındaki en belirgin farkı kümeleme işlemi, sınıflama işlemine benzer şekilde belirlenmiş bir takım sınıflar doğrultusunda bölme yapmaması olarak gösterilir. Sınıflamada her bir veri; önceden bilinen çıktılar sonucunda denetimli olarak öğrenim gerçekleştirmektedir. Fakat, kümeleme işleminde tanımlanmış sinıflar mevcut değildir (Dolgun, 2006). Kümeleme yöntemleri, Bölümleme yöntemleri 
(Partitioning methods), Hiyerarşik yöntemler (Hierarchical methods), Model tabanlı yöntemler (Model-based methods) olarak bilinmektedir.

3. Birliktelik Kuralları (Association Rules): Hareketli veri tabanlarındaki nesneler seti arasındaki yaygın örüntüleri, birliktelikleri, korelasyonları ve tesadüfi yapıları bulmak için kullanılan tekniklerdir (Chen ve ark. , 2005). Birliktelik kurallarının kullanıldığı en yaygın ve en bilinen örnek uygulaması olarak market sepeti bilinmektedir. Birliktelik durumlarının açığa çıkarılması, müşterilerin hangi ürünleri hangi ürünler ile satın almış oldukları tespit edilir ve işletme yönetimleri tarafından değerli bilgiye odaklanarak etkin satış stratejileri geliştirebilirler (Özekes, 2001). En bilinen birliktelik kuralı algoritması Apriori algoritmasıdır.

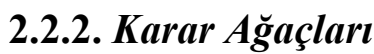

Karar ağaçları, uygulanmasının, yorumlanmasının ve entegrasyonunun kolay olması nedeniyle en yaygın kullanılan sınıflandırma tekniklerinden biridir (Argüden ve Erşahin, 2008). Bilgi teorisine dayanan karar ağaçları karmaşık ve bilinmeyen verileri kolay yorumlanmasını sağlayan modeller meydana getirmektedir. Bu bağlamda, bu çalışma da kolay yorumlanabilmesi, tahmin açısından güçlü olması sebebi ile karar ağacı algoritmaları kullanılmaktadır.

Karar ağaçları genellikle yaprakları ve gövdesi ile ağaç yapısında sunulmaktadır. Gövdeler özelliklerin koşullarını gösterirken yapraklar sınıflandırma sonuçlarını ortaya koyar.

Sınıflandırma ağaçları, verideki en önemli karakteristikleri tanımlar ve amaç değişkenine ulaşmak için en iyi tahmini sağlayan özelliklerin kombinasyonunu belirler. Ağacı yapılandırmak için, öncelikle popülasyon birbirinden mümkün olduğu kadar farklı 2 alt popülasyona ayrılır. Bunu yaparken, her bir karakteristiğe bakılır ve amaç değişkenin çıktılarının farklılaştıracak özelliklerin farklılaştırılması ile optimumu sağlayacak ayırım tanımlanır. Bu süreç, yavru popülasyonlara kadar tekrarlanır ( Seow ve Thomas, 2007).

Bağımlı değişkendeki farklılıkları en üste çıkacak şekilde veriyi sıralı bir biçimde farklı gruplara ayırmak karar ağaçlarının hedefidir. Karar ağacı, ağaç görünümünde olan bir teknik olarak bilinir. Aynı zamanda yukarıdan aşağıya doğru öğrenme sistemi olarak da bilinmektedir.

Karar düğümleri; dallar ve yapraklardan oluşmaktadır. Karar ağaçlarının yapısını oluşturan unsurlar (Argüden ve Erşahin, 2008):

- Karar düğümü: Veri setine uygulanan testi tanımlar. Her düğüm bir özelliğge sahip testi belirtmektedir. Test neticesinde ağacın dalları meydana gelir. Veri kaybının yaşanmasını önlemek için tüm verinin dahil olacağı sayıda dal belirlenmelidir. 
- Dal: Test sonucunu göstermektedir. Ortaya çıkan her dalın amacı; tanımlanacak sınıfın belirlenmesidir. Şayet, elde edilen dal sonucunda sınıflandırma belirlenemez ise karar düğümü tekrar oluşturulur.

- Yaprak: Dal; şayet bir sınıflandırmayı meydana getiriyor ise yaprak belirlenmiş olur. Yaprak, veriler ile istenen sınıflandırmanın; ortaya çıkardığı sınıflardan birini tanımlamaktadır.

Eğitim verisinde yer alan hangi alanların, hangi sıra ile kullanarak karar ağacının meydana getirileceği belirlenmelidir. Bu minvalde en sık kullanılan ölçüm Entropi ölçümü olarak bilinir. Ortaya çıkan sonuçların belirli ve karalı olması entropi ölçüsünün oranına bağlıdır. Entropi ölçüsünün fazla olması ortaya çıkan sonuçların o kadar kararsız olduğunu işaret etmektedir. $\mathrm{Bu}$ sebeple karar ağacının kökünde entropi ölçüsünün en az olduğu alanlar kullanılmaktadır (Özekes ve Çamurcu, 2002).

Karar ağacı algoritmaları her alanın bilgi kazancı hesaplayarak test alanına geçmektedir. Başka bir deyişle, en yüksek bilgi kazancına sahip olan alan test alanı olarak belirlenmektedir.

A alanı k farklı değere sahip olsun $\left\{\mathrm{a}_{1}, \mathrm{a}_{2}, \ldots, \mathrm{a}_{\mathrm{k}}\right\}$. Belirli bir A alanının entropi ölçüsünü veren formüller aşağıda yer almaktadır (Özekes ve Çamurcu, 2002):

$\mathrm{S}$, s adet veri örneğini barındıran bir set olsun. Sınıf etiketi alanının $m$ adet farklı $\mathrm{C}_{\mathrm{i}}(\mathrm{i}=1,2, \ldots, \mathrm{m})$ sınıfı tanımlayan $\mathrm{m}$ farklı değere sahip olduğunu düşünelim. $\mathrm{C}_{\mathrm{i}}$ sınıfında; $\mathrm{si}, \mathrm{S}$ 'nin örneklerinin sayısı olsun. Verilen örneği sınıflamak için ihtiyaç duyulacak beklenen bilgi verilmiştir.

Beklenen Bilgi: I $\left(s_{1}, s_{2}, \ldots, s_{m}\right)^{n}=-\sum_{i=1}^{m} \mathrm{p}_{\mathrm{i}} \log _{2}^{\mathrm{p}_{\mathrm{i}}}$

Burada $p_{i}$ bir örneğin $C_{i}$ sınıfına ait olması olasılı̆̆ıdır ve si $/ s$ ile tahmin edilir.

A alanı $\mathrm{k}$ farklı değere sahip olsun $\left\{\mathrm{a}_{1}, \mathrm{a}_{2}, \ldots, \mathrm{a}_{\mathrm{k}}\right\}$. Belirli bir A alanının entropi ölçüsünü veren formüller aşağıda yer almaktadır (Özekes ve Çamurcu, 2002):

$\mathrm{Bu}$ formülde;

$\mathrm{E}(\mathrm{C} \backslash \mathrm{A})=$ Sınıflama özelliğine sahip A alanının Entropi ölçüsünü,

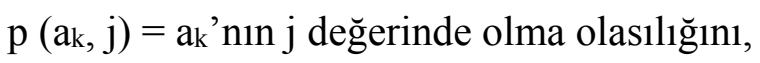

$p\left(c_{i} \backslash a_{k}, j\right)=a_{k}$ 'nın j. Değerinde olması durumunda sınıf değerinin $c_{i}$ olma olasılı̆̆ını,

$\mathrm{M}_{\mathrm{k}}=\mathrm{ak}_{\mathrm{k}}$ 'nın değerlerinin sayısının $; \mathrm{j}=1,2, \ldots, \mathrm{M}_{\mathrm{k}}$, olmasını

$\mathrm{N}=$ farklı sınıfların sayısının $; \mathrm{i}=1,2, \ldots, \mathrm{N}$, olması

$\mathrm{k}=$ alanların sayısının $; \mathrm{k}=1,2, \ldots, \mathrm{k}$, olmasını göstermektedir. 
Entropi: $\mathrm{E}(\mathrm{A})=\sum_{j=1}^{k} \frac{\mathrm{s}_{1 \mathrm{j}}+\cdots+\mathrm{s}_{\mathrm{mj}}}{\mathrm{s}} \mathrm{I}\left(\mathrm{s}_{1 \mathrm{j}}+\cdots+\mathrm{s}_{\mathrm{mj}}\right)$

Karar ağaçlarının en bilinen algoritmaları olan CART, CHAID, ID3, C4.5 algoritmalarıdır ki bu çalışmada WEKA programında C4.5 algoritmasının J48 olarak kodlanan versiyonu uygulanmıştır.

\section{Bulgular ve Tartışma}

\subsection{Veri Hazırlanması}

Bir havayolu işletmesinde 2015 yılında kabin memurlarının her 3 aylık dönemlerde kabin amirleri tarafından belirli yetkinliklerde değerlendirilmesi sonucunda kurumsal karneleri yayımlanmaktadır. Değerlendirmeler neticesinde kabin memurlarının istatistik hesaplamalar ile harf bazında düzeyleri ve puanları belirlenmektedir. Çalışmada bağımlı değişken olarak kullanılmak üzere; her 3 aylık dönemde yayımlanan karne düzeyleri, yıl bazında tek bir karne düzeyi halinde oluşturulmuştur. Aynı zamanda her 3 aylık dönemde yayımlanan kurumsal karnede var olan 10 alt yetkinlik puanları da yıl bazında birleştirilmiştir. Bu sayede her bir alt yetkinliğin 4 dönem boyunca puanları ayrı ayrı çalışılmaktansa yıl bazında tek bir puan halinde daha efektif şekilde çalışılmıştır. $\mathrm{Bu}$ bağlamda kabin memurlarının karne düzeylerinin; hangi alt yetkinliğe ve hangi demografik özelliğe bağlı olduğu sınıflandırma algoritmalarından karar ağaçları yöntemleri ile belirlenmiştir. Verilerin temin edildiği kaynak güvenli bir kaynak olmasının avantajı ile kapsamlı bir şekilde veriler analiz edilmiştir. Değişkenler demografik ve yetkinlik bazda olmasından dolayı 18 adet değişkenin anlamı (bağımlı değişken dahil olmak üzere) ve veri hazırlama safhasında kullanılan açıklamaları incelenmiştir.

Çalışmada kullanılan demografik değişkenler aşağıda yer almaktadır:

1. Kabin memuru numarası: Kabin memurlarına ait gizlilik prensibinin korunması amacıyla; her bir kabin memurunun numarası 1 den başlatılarak sırası ile 1 arttırılarak nümerik hale getirilmiştir. $\mathrm{Bu}$ sayede çalışmada kullanılan kabin memuru verilerinin kime ait olduğunun bilinmesinin önüne geçilmiştir.

2. Sınıf: Kabin memurlarının tecrübe ve performanslarına göre sınıf değişiklikleri yapılmaktadır. Çalışmada “Z,E,Y,N,Q” olarak belirtilmiştir.

- Z sınıfi kabin memuru: Tecrübeli dar gövde uçaklarda görevli kabin memuru

- E / Y sınıfi: Tecrübeli geniş gövde uçaklarda görevli kabin memuru.

- Q sinıfi: Business sinıfinda tecrübeli kabin memuru 
- N sinıfi: Mahalli dil bilen tecrübeli kabin memuru.

3. Tecrübe: Kabin memurlarının işe başladıkları tarihten itibaren yıl olarak tecrübe süresi.

4. Yaş: Kabin memurlarının yaşı. En küçük yaş; 22, en büyük yaş: 54 olmasından dolayı uygulanacak karar ağacı algoritmalarından fazla dallanmaya sebep olmamasından dolayı kategorik hale getirilmiştir.

Tablo 1.Yaş değişkeninin tanımlanması

\begin{tabular}{cc}
\hline Yaş aralığ1 & Uygulama tanımı \\
\hline "20-29" & "22-30 YAS" \\
"30-39" & "31-39 YAS" \\
"40-49" & "40-49 YAS" \\
"50" & "50 YASVEUSTU" \\
\hline
\end{tabular}

5. Cinsiyet: Kabin memurlarının cinsiyeti. Uygulamada kadın "K" ve erkek "E" olarak tanımlanmıştır.

6. Medeni Hal: Kabin memurlarının medeni durumu. Evli ve bekar olarak iki kategoride ele alınmıştır. Sırasıyla "E” ve "B" olarak tanımlanmıştır.

7. Eğitim: Kabin memurlarının öğrenim durumu. Öğrenim durumlarına göre 5 farklı tanımlama yapılmıştır.

Tablo 2. Eğitim değişkeninin tanımlanması

\begin{tabular}{cc}
\hline Öğrenim durumu & Uygulama tanımı \\
\hline Lise & 3 \\
Yüksekokul & 4 \\
Üniversite & 5 \\
Yüksek Lisans & 6 \\
Doktora & 7 \\
\hline
\end{tabular}

Çalışmada kullanılan mesleki yetkinlik değişkenleri ise aşağıda yer almaktadır. Her mesleki yetkinlik kriteri için, her dönemde en az 1 en fazla 5 puan üzerinden değerlendirme yapılmaktadır. Her üçer aylık dönemde belirli olan 10 alt yetkinliğin puanları, yıl bazında hesaplanmış ve ortalamaları alınmıştır. 2015 yılı boyunca 4 dönem bulunmasından dolayı, her bir değişken için en az 4 en fazla 20 puan olarak hesaplanmaya çalışılmıştır. İlgili yetkinlik değişkeni puanlarında 4 dönem boyunca puanı olmayan veriler, eksik veri olarak değerlendirildiği için veri hazırlaması safhasında gürültülü ve kayıp değerlerden elimine edilmiş bir veri seti hazırlanmıştır. 
8. KF1 (Kurumsal Farkındalık_1) : Kabin memurlarının performans değerlendirmelerinde yetkinlik ölçütlerinden biri olup "Davranış konusunda ve havayolumuzu temsil etme açısından örnek bir kabin memurudur” kriterinin ölçümlendiği değişkendir.

9. KF2 (Kurumsal Farkındalık_2) : Kabin memurlarının performans değerlendirmelerinde yetkinlik ölçütlerinden biri olup "Görüntü ve kişisel bakım açısından örnek bir kabin memurudur" kriterinin ölçümlendiği değişkendir.

10. EI1 (Etkili İletişim_1) : Kabin memurlarının performans değerlendirmelerinde yetkinlik ölçütlerinden biri olup “Ekip arkadaşlarıyla ve yolcularımızla doğru iletişim kurdu” kriterinin ölçümlendiği değişkendir.

11. EI2 (Etkili İletişim_2) : Kabin memurlarının performans değerlendirmelerinde yetkinlik ölçütlerinden biri olup "Yolcularımızı güler yüzle karşıladı, uçuş boyunca güler yüzle hizmet etti " kriterinin ölçümlendiği değişkendir.

12. AP (Analiz Etme ve Problem Çözme): Kabin memurlarının performans değerlendirmelerinde yetkinlik ölçütlerinden biri olup "Görev esnasında karşılaştığı problemleri çözebildi. Görevi boyunca yolcularımıza alternatif sundu. " kriterinin ölçümlendiği değişkendir.

13. SO (Sürekli Öğrenme ve Kişisel Gelişim): Kabin memurlarının performans değerlendirmelerinde yetkinlik ölçütlerinden biri olup “Öğrenmeye ve eleştiriye açık bir kabin memurudur. " kriterinin ölçümlendiği değişskendir.

14. TR1 (Takım Ruhu ve Dayanışma_1): Kabin memurlarının performans değerlendirmelerinde yetkinlik ölçütlerinden biri olup "Ekiple uyumlu çalıştı, görev alanının dışında da ekip arkadaşlarına yardımcı oldu ” kriterinin ölçümlendiği değişkendir.

15. TR2 (Takım Ruhu ve Dayanışma_2): Kabin memurlarının performans değerlendirmelerinde yetkinlik ölçütlerinden biri olup "Sorumluluk bilinciyle görevlerini tam ve zamanında yerine getirdi” kriterinin ölçümlendiği değişkendir.

16. MO1 (Müşteri Odaklılık_1): Kabin memurlarının performans değerlendirmelerinde yetkinlik ölçütlerinden biri olup "Ürün, hizmet ve hat bilgilerine hakim, yolcularımıza doğru ve zamanında hizmet sundu" kriterinin ölçümlendiği değişkendir.

17. MO2 (Müşteri Odaklılık_2): Kabin memurlarının performans değerlendirmelerinde yetkinlik ölçütlerinden biri olup "Yolcularımızın talebi olmadan hizmet sunmayı teklif edebildi. Servis öncesinde ve sonrasında yolcularımızın taleplerinin karşılanabilmesi için ulaşılabilir durumdayd1." kriterinin ölçümlendiği değişkendir.

18. Y1llık karne düzeyi: 2015 yılı kabin memurlarının performans değerlendirmelerinin sunulduğu karne düzeyidir. Uygulamada hedef değişken (bağımlı değişken) olarak tanımlanmıştır. 
Tablo 3.Karne düzey değişkeninin tanımlanması

\begin{tabular}{ccc}
\hline Karne & Düzeyi & Uygulama Tanımı \\
\hline A & 4 \\
B1 & 3 \\
B2 & 3 \\
C1 & 2 \\
C2 & 1 \\
D1 & 1 \\
\hline
\end{tabular}

Tüm değişkenlerin WEKA programında sağlıklı bir sonuç vermesi için doğru tanımlanma yapılmaya gayret edilmiştir. Öyle ki, çalışmada mesleki yetkinlikler olan KF1,KF2,EI1,EI2,AP, SO,TR1,TR2,MO1,MO2 nominal değişken olarak tanımlanmış akabinde karar ağacı algoritmaları uygulanmıştır. Doğru olarak sınıflandırılan kayıt oranının en yüksek olan algoritma J48 olarak seçilmiştir. J48 çıktılarına bakıldığı zaman ağaç boyutunun 215 olarak sonuçlanmasından dolayı algoritma çıktısının yorumlanması güçlenmiştir. $\mathrm{Bu}$ nedenle bahse konu olan mesleki yetkinlik değişkenleri yukarıda belirtildiği gibi tanımlamalarının nümerik olarak değiştirilerek veri hazırlanması tamamlanarak uygulama sürdürülmüştür.

Böylece, 2015 yılı Ocak-Aralık ayları için 18 farklı değişken için 3764 x 18'lik bir veri kümesi elde edilmiştir.

\subsection{WEKA ‘ da Sınıflandırma Algoritmalarının Uygulanması ve Algoritma Sonuçları}

$\mathrm{Bu}$ çalışmada 8 farklı sınıflandırma algoritması denenmiş ve doğruluk oranları ve model oluşum zamanını içeren elde edilen sonuçlar Tablo 4'de yer almaktadır.

Tablo 4. Sınıflandırma algoritmalarının karşılaştırılması

\begin{tabular}{|c|c|c|c|c|c|c|c|c|c|c|c|}
\hline & $\begin{array}{c}\text { Doğru } \\
\text { Sınıflandırılan } \\
\text { örnek }\end{array}$ & $\begin{array}{c}\text { Kappa } \\
\text { istatistiği }\end{array}$ & $\begin{array}{l}\text { Ort. } \\
\text { mutlak } \\
\text { hata }\end{array}$ & $\begin{array}{c}\text { Ort. } \\
\text { mutlak } \\
\text { hata } \\
\text { karekök }\end{array}$ & $\begin{array}{c}\text { Göreli } \\
\text { mutlak } \\
\text { hata } \\
(\%)\end{array}$ & $\begin{array}{c}\text { Göreli } \\
\text { hata } \\
\text { karekök } \\
(\%)\end{array}$ & $\begin{array}{l}\text { Model } \\
\text { Zamanı }\end{array}$ & TP & FP & $\begin{array}{c}\text { F- } \\
\text { ölçütü }\end{array}$ & ROC \\
\hline $\mathrm{J} 48$ & 3565 & 0,88 & 0,04 & 0,15 & 16,45 & 44,43 & $0,36 \mathrm{sn}$ & 0,947 & 0,064 & 0,946 & 0,964 \\
\hline $\begin{array}{l}\text { Naive } \\
\text { Bayes }\end{array}$ & 3557 & 0,88 & 0,03 & 0,16 & 12,47 & 46,74 & $0,06 \mathrm{sn}$ & 0,945 & 0,044 & 0,949 & 0,99 \\
\hline OneR & 3535 & 0,86 & 0,03 & 0,17 & 13,58 & 52,13 & $0,05 \mathrm{sn}$ & 0,939 & 0,069 & 0,938 & 0,935 \\
\hline ZeroR & 2517 & 0,00 & 0,22 & 0,33 & 100,00 & 100,00 & $0,06 \mathrm{sn}$ & 0,669 & 0,669 & 0,536 & 0,498 \\
\hline $\begin{array}{c}\text { Random } \\
\text { Tree }\end{array}$ & 3529 & 0,86 & 0,03 & 0,17 & 14,82 & 51,20 & $0,11 \mathrm{sn}$ & 0,938 & 0,068 & 0,938 & 0,938 \\
\hline $\begin{array}{l}\text { Multilayer } \\
\text { Perceptron }\end{array}$ & 3557 & 0,88 & 0,03 & 0,15 & 13,04 & 45,76 & $154 \mathrm{sn}$ & 0,945 & 0,067 & 0,942 & 0,982 \\
\hline $\begin{array}{c}\text { Random } \\
\text { Forest }\end{array}$ & 3576 & 0,89 & 0,03 & 0,14 & 14,91 & 40,58 & $4 \mathrm{sn}$ & 0,95 & 0,061 & 0,95 & 0,988 \\
\hline $\begin{array}{l}\text { Decision } \\
\text { Stump }\end{array}$ & 3506 & 0,85 & 0,06 & 0,18 & 27,12 & 53,25 & $0,08 \mathrm{sn}$ & 0,931 & 0,079 & 0,928 & 0,924 \\
\hline
\end{tabular}


İlgili tabloya göre; belirtilmiş olan sınıflandırma algoritmaları kullanılarak elde edilmiş performans sonuçlarına yer verilmiştir.10 katlı çapraz doğrulama ile yapılan sınıflandırma analizinde 100 ağaç türetilerek edinilen Random Forest birinci sınıftaki doğru sınıflandırılan kayıt TP (True Positive) oranı \%95,0053, ikinci sınıftaki kayıtların sayısını veren FP (False Positive) 0,061 olarak en iyi sınıflandırma başarısını elde etmiştir. Sınıflandırma doğruluğu açısından 2. Sırada ise J48 karar ağacı algoritması bulunmaktadır. ROC eğrisine göre; eğri altında kalan alan 1'e yaklaştığ 1 takdirde testin doğruluğu artmaktadır. Random Forest ve J48 algoritmasının ROC eğrisi altında kalan alanları karşılaştırıldığı zaman; RF algoritması için 0,988 olarak, J48 algoritması için 0,964 olarak tespit edilmiştir. $\mathrm{Bu} 2$ algoritmayı ayrıca model oluşum zamanları bakımından mukayese edildiğinde J48 algoritması, Random Forest algoritmasına göre daha kısa sürede sonuç verdiği tespit edilmiştir.

\subsection{J48 algoritmasına göre sonuçların yorumlanması}

WEKA’ da analiz edilen J48 algoritmasına göre ilk dallanmanın SO ( Sürekli Öğrenme ve Kişisel Gelişim) olduğu görülmektedir. Yetkinliklere göre değerlendirilen kabin memurlarının; ilgili değişkenlerden hangilerinin ne ölçüde karne düzeylerini etkilediğini hedefleyen çalışmada ilk dallanma olan sürekli öğrenme ve kişisel gelişimin akabinde kabin memurlarının davranış konusunda temsil kabiliyetlerini geliştirmeleri öncelikli olarak belirlenen durum olmuştur. Nitekim, bu değişken ile müşteri odaklılık değişkeni arasında karne düzeyleri üzerinde benzer etkisi olduğu görülmüştür. Temsil kabiliyeti ile yolcuları güler yüzle karşılama arasında güçlü bir bağıntı olduğu ve karne seviyesini etkilediği görülmüştür.

Görevlerini tam ve zamanında yerine getirme konusunda aksaklık gösteren bir kabin memurunun yolcuya karşı güler yüzlü hizmet vermesi ve davranışları ile temsil kabiliyetinin yüksek olması sonucu ve karne puanı iyi olarak tespit edilmiştir. Bu durumda olan kabin memurları için sadece zaman yönetimi eğitimi önerilebilmektedir. Ayrıca, demografik verilerin karne düzeylerine etki etmediği, anlamlı bir kural oluşturmadığı saptanmıştır.

\subsection{Random Forest algoritmasına göre sonuçların yorumlanması}

Random Forest ile 3 farklı algoritma kullanılarak edinilen karar ağaçları ile 50, 100, 150 ağaç türetilmesi ile bu algoritmaların sonuçları karşılaştırılmıştır. 
Tablo 5. Random Forest Algoritma Sonucu

\begin{tabular}{lcl} 
& $\begin{array}{c}\text { Doğru } \\
\text { Sinıflandırılan kayıt (\%) }\end{array}$ & $\begin{array}{l}\text { Model } \\
\text { Oluşum } \\
\text { Zamanı }\end{array}$ \\
\cline { 2 - 3 } $\begin{array}{l}\text { Random Forest } \\
(50 \text { Ağaç) }\end{array}$ & 95,1116 & 1,84 saniye \\
\hline $\begin{array}{l}\text { Random Forest } \\
(100 \text { Ağaç })\end{array}$ & 95,0053 & 3,19 saniye \\
\hline $\begin{array}{l}\text { Random Forest } \\
(150 \text { Ağaç })\end{array}$ & 94,9522 & 5,02 saniye \\
\hline
\end{tabular}

Random Forest yönteminde en iyi performans sonuçlarının sınıflama doğruluğu bakımından 50 ağaç türetilerek edinildiği belirlenmiştir. Ağaç sayısının artmasıyla beraber doğru sınıflandırılan kayıt yüzdesinin azaldığı tespit edilmiştir. Ayrıca modelleme sürelerine bakıldığında sınıflandırma doğruluğu ile aynı orantıda olduğu gözlemlenmiştir. Karar ağacı gibi görsel bir sonuç vermeyip algoritma adımlarını görülmeyecek şekilde vererek karmaşık bir yapı oluşmasından dolayı çalışma J48 algoritmasına göre yorumlanmıştır.

Ayrıca, kabin memurlarının karne düzeylerini (A, B1,B2,C1,C2, D1) etkileyen nitelik için en önemli olan diğer niteliklerin belirlenmesi amacıyla, WEKA programında nitelik seçimi özelliği ile 2 defa aşağıda belirtilen algoritmalar ile "BestFirst" ve "Ranker" metotları uygulanması sonucunda çıktıların J48 algoritması çıktıları ile aynı doğrultuda olduğu tespit edilmiştir. "InfoGainAttributeEval" algoritması sonucunda en yüksek nitelik olarak belirlenen "SO”, J48 algoritmasında da ilk dallanma değişkenidir. Kabin memurlarının karne düzeyleri için demografik verilerin anlamlı bir değişken olmadığı görülmüştür. J48 ve nitelik seçme algoritmalarıda aynı doğrultutadır.

\begin{tabular}{|c|c|cc|}
\hline $\begin{array}{c}\text { Nitelik Seçimi } \\
\text { (Attribute Evaluator) }\end{array}$ & $\begin{array}{c}\text { Metod } \\
\text { (Search Method) }\end{array}$ & \multicolumn{2}{|c|}{ Sonuç } \\
\hline CfsSubsetEval & Best First & SINIF, KF1,KF2,EI2, AP,SO,TR2,MO1,MO2 \\
\hline & & 0.66246 & SO \\
& & 0.65239 & MO1 \\
& & 0.635273 & TR2 \\
& & 0.632395 & KF1 \\
& \multirow{3}{*}{ Ranker } & 0.628692 & MO2 \\
& & 0.617676 & AP \\
& & 0.601472 & EI2 \\
& & 0.583548 & TR1 \\
& & 0.566257 & EI1 \\
& & 0.477559 & KF2 \\
& & 0.169042 & SINIF \\
& & 0.005775 & EGITIM
\end{tabular}




\section{Sonuçlar ve Öneriler}

Günümüz işletmelerinde mevcut müşterileri elde tutma çabaları, onların memnuniyetleri için taleplerini değerlendirme ve beklentileri karşılama çalışmaları rekabet ortamında var olabilmesi gerekli şartlardan biridir.

Her geçen gün insanların daha fazla tercih ettiği havayolu taşımacılığında yolcuların her bir seyahat deneyiminin bir öncekinden daha iyi olması ve ihtiyaçlarının karşılaması, bir sonraki seyahatinde aynı havayolu işletmesine seçmesine neden olmaktadır.

Bir havayolu işletmesinde aktif olarak uygulanmakta olan dış hat tarifeli uçuşlardan sonra kabin memurları 6 ayrı yetkinlikte ve bu yetkinliklerin alt yetkinliği olan toplam 10 ayrı alt yetkinlik ile değerlendirilmektedirler. Bir yılda üçer aylık toplam 4 dönem için bu yetkinliklerde değerlendirme puanları neticesinde kurumsal karneleri yayımlanmaktadır. Bu bağlamda 2015 yılı Ocak- Aralık ayları içerisinde 3764 kabin memurunun mesleki yetkinlikleri ve demografik verileri ile yıllık karne düzeyleri (4 dönemde yayımlanan karne düzeyleri yıl bazında tek bir karne düzeyi olarak hesaplanmıştır) arasında anlamlı kurallar çıkarma noktasında veri madenciliği yöntemlerinden biri olan karar ağaçları kullanılmış ve bu uygulama ile literatüre katkı sağlayacağı düşünülmüştür. Öyle ki, havacılık sektöründe, performans değerlendirme uygulamalarında veri madenciliği yöntemlerinin uygulanması konularında literatürde oldukça az çalışma bulunmaktadır. İncelenen çalışmalarda ise yolcu memnuniyetine etki eden dış faktörlerden yola çıkarılarak sürdürülmüş çalışmalar bulunmaktadır. Bu çalışmada ise yolcu memnuniyeti ve bağl1lığı için yadsınamaz payı olan kabin ekiplerinin performans değerlendirmelerinden yola çıkılarak çalışma yapılmıştır. $\mathrm{Bu}$ bağlamda kabin memurlarının performans değerlendirmelerinde en önemli değişkenin ne olduğu tespit edilmeye çalışılarak kabin memurlarının kariyer gelişimlerine ve yolcu memnuniyetine katkı sağlama amaçlanmıştır.

10 katlı çapraz doğrulama ile yapılan sınıflandırma analizinde 100 ağaç türetilerek edinilen Random Forest \%95,0053 oranı ile en başarılı algoritma akabinde \%94,70 oranı ile J48 karar ağacı algoritması belirlenmiştir.

Random Forest algoritmasının J48 algoritmasına göre daha uzun modelleme süresi olması ve karar ağacı gibi görsel bir sonuç vermeyip algoritma adımlarını görülmeyecek şekilde vererek karmaşık bir yapı oluşmasından dolayı J48 algoritma çıktıları gözlemlenmiştir. 
J48 algoritmasında ilk dallanma Sürekli Öğrenme ve Kişisel Gelişim (SO) değişkeni ile başlamıştır. Nitekim, aynı şekilde WEKA'da uygulanan nitelik seçimi algoritmalarında da aynı doğrultuda çıktı vermiştir.J48 algoritmasının sonuçlarına göre, sürekli öğrenme ve kişisel gelişimden sonra kurumsal temsil ve yolcuya doğru ve zamanında hizmet sunma konuları karne seviyesini önemli etkileyen değişkenler olmuştur.

Kabin memurlarının performans değerlendirmesinde gerçekleştirilen uçuş bazında bir üst amirinin değerlendirmeleri ile birlikte yolcunun direkt olarak hizmet aldığı kabin memurunu değerlendirerek bu çıktıları bir bütün olarak ele alıp veri madenciliği yöntemleri ile analiz edilmesi; ilerleyen dönemlerde gerçekleşecek olan çalışmalarda literatüre katkı sağlayacağı düşünülmektedir.

\section{Teșekkür}

$\mathrm{Bu}$ çalışmada bana sonsuz destek veren çok sevgili aileme ve danışman hocam Doç. Dr. Sn.Uğur ÖZCAN'a teşekkürlerimi sunarım.

\section{Kaynaklar}

Alataş, B., Akın, E., (2004). Veri madenciliğinde yeni yaklaşımlar. Ya/Em-2004- Yöneylem Araştırması/Endüstri Mühendisliği XXIV Ulusal Kongresi, Gaziantep-Adana.

Alkoç, H., (2004). Havayolu İşletmelerinin Hizmet Kalite Açısından Değerlendirilmesi Üzerine Bir Pilot Araştırma: Türk Hava Yolları Uygulaması, İstanbul Üniversitesi, Pazarlama Anabilim Dalı, Yüksek Lisans Tezi, İstanbul.

Argüden, Y., Erşahin, B., (2008). Veri Madenciliği Veriden Bilgiye, Masraftan Değere. İstanbul: ARGE Danışmanlık A.Ş, s.22-23.

Chen, Y., L., Tang, K., Shen, R., J., and Hu, Y., H., (2005). Market basket analysis in a multiple store environment. Decision support systems, 40(2): 339-354.

Dolgun, M., Ö., (2006). Büyük alışveriş merkezleri için veri madenciliği uygulamaları. Yüksek Lisans Tezi, Hacettepe Üniversitesi Fen Bilimleri Enstitüsü, Ankara, 23-27.

Emekci, F., Sahin, O. D., Agrawal, D., El Abbadi, (2007). Privacy preserving decision tree learning over multiple parties, Data \& Knowledge Engineering, 63, 348-361.

Furnham, A., (1991). Personality and occupational success: 16PF correlates of cabin crew performance. Personality and Individual Differences, 12(1), 87-90.

Gencer, C., \& Çetin, T. (2011). Kurumsal Performans Karnesi ve Havacılık Sektöründe Bir Uygulama. Savunma Bilimleri Dergisi, 10(2), 105-121.

Gobena M., (2000). Flight Revenue Information Support System for Ethiopian Airlines. A Thesis Submitted in Partial Fulfillment of the requirement for the Degree of M.Sc.I.S. Addis Ababa University: Addis Ababa.

Hatipoğlu, S. ve Işık, E. S., (2015). Havayolu Ulaşımında Hizmet Kalitesinin Ölçülmesi: İç Hatlarda Bir Uygulama. KSÜ Sosyal Bilimler Dergisi, 12(2), 293-312.

Hsu, M. H., 2(008). A personalized English learning recommender system for ESL students, Expert Systems with Applications, 34, $683-688$.

Kalıkov, A., 2(006). Veri madenciliği ve bir e-ticaret uygulamast. Yüksek Lisans Tezi, Gazi Üniversitesi Fen Bilimleri Enstitüsü, Ankara, 22-38.

Mitra, S., Acharya, T., (2003). Data mining : multimedia, soft computing , and bioinformatics John Wiley \& Sons Publisher. 
Nameghi, E. N., \& Ariffin, A. A. M. (2013). The measurement scale for airline hospitality: Cabin crew's performance perspective. Journal of Air Transport Management, 30, 1-9.

Okumuş, A , Asil, H . (2007). Havayolu Taşımacılığında Yerli ve Yabancı Yolcuların Memnuniyet Düzeylerine Göre Beklentilerinin İncelenmesi. Kocaeli Üniversitesi Sosyal Bilimler Enstitüsü Dergisi, (13), 152-175.

Özekes, S., 2(001). Veri Madenciliği Modelleri ve Uygulama Alanları. Ístanbul Ticaret Üniversitesi Dergisi, 2003: 65-82.

Özekes, S., ve Çamurcu, A.Y., (2002). Veri Madenciliğinde Sinıflama ve Kestirim Uygulaması. T.C. Marmara Üniversitesi Fen Bilimleri Dergisi, 18, 159-174.

Piatetsky-Shapiro, G., (1990). Knowledge Discovery in Real Databases: A Report on the IJCAI-89 Workshop. AI Magazine, 11(5): 68-70.

Pritscher, L. and Feyen, H., (2011). Data Mining and Strategic Marketing in the Airline Industry. http://www.luc.ac.be/iteo/articles/pritscher1.pdf

Seow, H. V., Thomas, L. C., (2007). To ask or not to ask, that is the question. European Journal of Operational Reserch, 183, $1513-1520$.

Yılmaz, A. K., Durak, M. Ş., Özdemir, E., Kiracı, K., \& Tanrıverdi, G., (2017). Eskişehir ilinde havayolu yolcu potansiyelinin belirlenmesi üzerine bir karar ağacı uygulaması. Anadolu University of Sciences \& Technology-B: Theoretical Sciences, 5(1). 